\title{
Current state of the art in the diagnosis and surgical treatment of Cushing disease: early experience with a purely endoscopic endonasal technique
}

\author{
Amir R. Dehdashti, M.D., AND Fred Gentili, M.D., F.R.C.S.C. \\ Division of Neurosurgery, Toronto Western Hospital, University of Toronto, Ontario, Canada
}

\begin{abstract}
Object. Transsphenoidal pituitary surgery is the primary therapy for Cushing disease because of its potential to produce lasting remission without the need for long-term drug or hormone replacement therapy. The authors evaluated the current role of pure endoscopic endonasal pituitary surgery in the treatment of Cushing disease.

Methods. Twenty-five patients underwent pure endoscopic surgery for confirmed Cushing disease. Thirteen patients had microadenomas and seven had macroadenomas; magnetic resonance images obtained in five patients were only suspicious or nondiagnostic, and thus they underwent inferior petrosal sinus sampling. Two patients had evidence of cavernous sinus involvement. Final histological results were consistent with adrenocorticotropin hormone $(\mathrm{ACTH})-$ secreting adenoma in 20 patients.

Results. Twenty patients $(80 \%)$ had clinical remission and laboratory confirmation of hypocortisolemia (serum cortisol $<100 \mathrm{nmol} / \mathrm{L}$ requiring substitution therapy), suppression to low-dose dexamethasone, and normal 24-hour urinary free cortisol. The median follow-up period was 17 months (range 3-32 months). There was no recurrence at the time of the last follow-up. Three patients presented with new anterior pituitary deficiency, but no one had permanent diabetes insipidus. In one patient a cerebrospinal fluid leak developed but later resolved following lumbar drainage. Treatment failure was attributable to involvement of the cavernous sinus in two patients, incomplete tumor removal in one, negative exploration in one, and nodular corticotroph hyperplasia of the pituitary gland in one.

Conclusions. Early results indicated that endoscopic endonasal surgery is a safe and effective treatment for ACTH-producing adenomas. The rate of remission in this study is comparable to those in previous series, and the rate of major postoperative complications is extremely low. Further studies with a larger number of patients and longer follow-ups are required to determine whether this more minimally invasive pure endoscopic approach should become the standard of care for the surgical treatment of Cushing disease. (DOI: 10.3171/FOC-07/09/E9)
\end{abstract}

\section{KEY WORDS • adrenocorticotropin hormone-secreting adenoma • Cushing disease • endoscopic surgery $\bullet$ minimally invasive surgery $\bullet$ outcome $\bullet$ transsphenoidal approach}

$\mathrm{W}$ ITHIN the field of pituitary surgery, Cushing disease has a special place. The diagnosis of central Cushing disease is based on a variety of static and sophisticated dynamic endocrinological tests on which the indication for surgery is ultimately based. Selective

\footnotetext{
Abbreviations used in this paper: $\mathrm{ACTH}=$ adrenocorticotropin hormone; $\mathrm{CSF}=$ cerebrospinal fluid; FSH = follicle-stimulating hormone; GTR = gross-total resection; IGF-1 = insulin-like growth factor-1; IPSS = inferior petrosal sinus sampling; $\mathrm{LH}=$ luteinizing hormone; $\mathrm{MR}=$ magnetic resonance; $\mathrm{TSH}=$ thyroid-stimulating hormone; UFC = urinary free cortisol.
}

transsphenoidal adenectomy is considered the first treatment option in the majority of patients, with long intervals of endocrine and clinical remission having been observed thereafter. Despite advances in diagnosis and imaging and surgical techniques, even in the hands of experienced pituitary surgeons, no convincing improvement in remission rates has been achieved during the last two decades. A lack of consensus regarding the definition of remission of hypercortisolism and its still poorly understood pathophysiology may be factors. ${ }^{5}$ Long-term follow-up study data have shown that the quality of life in patients in remission after the first pituitary surgery is better than in those who need additional treatments. ${ }^{28}$ Thus, successful initial treatment is highly desirable in Cushing disease. In several microsurgi- 
cal studies the remission rates have varied between 42 and $95 \%$, with recurrence rates between 3 and $63 \%$. Complications have been reported in up to $53 \%$ of cases. ${ }^{1-4,6,12}$, $16,20,38,40-42,45$

The introduction of the endoscope has opened a new chapter in the treatment of pituitary tumors. The main advantages of endoscopic transsphenoidal surgery include the wide panoramic view offering better visualization of critical structures and the absence of retractors with the subsequent potential for reduced complications. Researchers using the endoscopic technique have recently shown an overall improvement in tumor resection and remission rates in pituitary adenoma surgery., ${ }^{7,919,26,32}$ It has yet to be determined whether this technique, along with other advances in technology (for example, neuronavigation, intraoperative MR imaging, and radiosurgery), will improve the overall cure rate and long-term outcomes in patients with functioning adenomas, particularly with regard to those affected by Cushing disease.

The objective in this paper is to demonstrate the current state of the art in the diagnosis of Cushing disease and report our early results using a purely endoscopic approach in the surgical treatment of this pathophysiology. Our results are compared with those reported in the current literature. Specifically, the role of the endoscopic approach is compared with the standard microscopic technique.

\section{Clinical Material and Methods}

Between June 2004 and March 2007, 25 consecutive patients with confirmed primary Cushing disease were treated using a purely endoscopic endonasal approach at the Division of Neurosurgery, Toronto Western Hospital, University of Toronto. Diagnoses were made based on the criteria mentioned below.

\section{Current Diagnosis of Cushing Disease}

Dynamic endocrine function tests were used to establish the diagnosis: A fasting morning basal cortisol level greater than $100 \mathrm{nmol} / \mathrm{L}$ after the administration of $2 \mathrm{mg}$ dexamethasone at 10:00 p.m. the previous day leads to a diagnosis of Cushing syndrome. The pituitary origin of the disease is proven by suppression of the cortisol level to less than $50 \%$ of the original value after the administration of 8 to $32 \mathrm{mg}$ dexamethasone. ${ }^{27,44}$ An elevated UFC test $(\geq 300$ $\mu \mathrm{g} / 24$ hours ) is also done and is indicative of Cushing disease. ${ }^{46}$ Anterior pituitary lobe function is further assessed by determining serum levels of prolactin, TSH, triiodothyronine, thyroxine, LH, FSH, and ACTH plasma levels as well as cortisol serum levels before and after ACTH stimulation following an overnight fast.

Thin-cut MR images (2 mm; T1- and T2-weighted images in the coronal and sagittal planes) of the sellar region were obtained to confirm a sellar tumor (Fig. 1). If the findings were not definitive, 3-tesla MR imaging with dynamic studies was requested. If there was still doubt regarding either the presence or the pituitary origin of the disease, IPSS combined with selective catheterization of the abdominal and thoracic veins was performed, and ACTH and cortisol plasma levels were determined. Thus, hypercortisolism of adrenal origin or ectopic or paraneoplastic ACTH production could be ruled out. A greater than twofold central to peripheral gradient of ACTH levels ( $\geq$ threefold

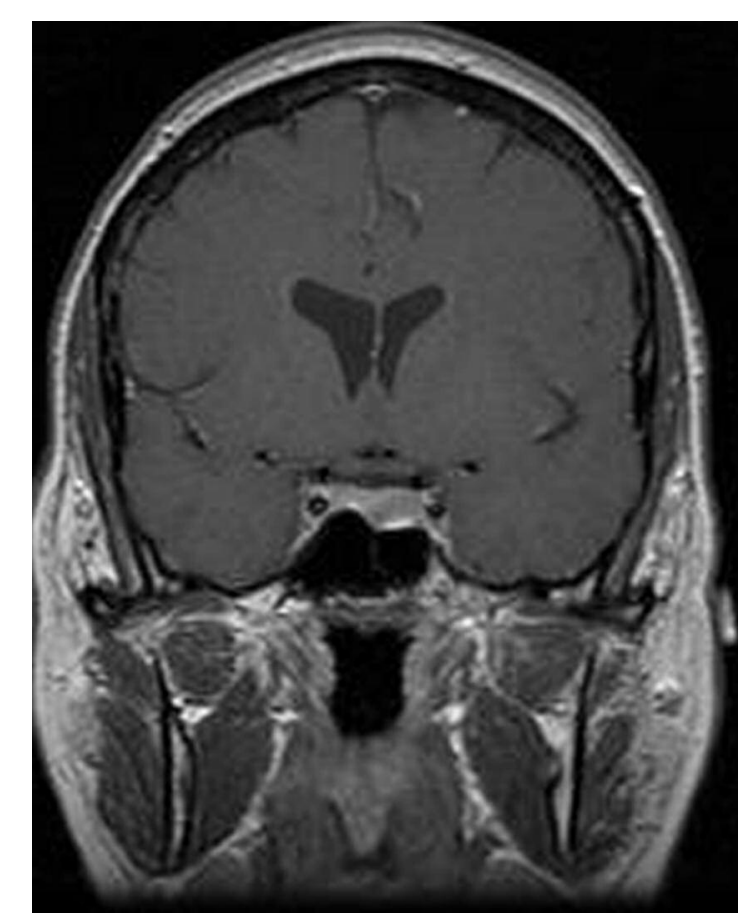

FIG. 1. Coronal Gd-enhanced T1-weighted MR image obtained in a patient with Cushing disease, showing a macroadenoma on the left side of the pituitary fossa.

after corticotropin-releasing hormone stimulation) on the IPSS study is highly suggestive of a pituitary source, and a more than 1.4-fold interpetrosal gradient indicates the side of the tumor. ${ }^{33}$ In $15 \%$ of cases, IPSS can be nondiagnostic because of technical problems with the catheterization. More problematic is the fact that in up to one third of patients, the predicted side of a pituitary adenoma is false. ${ }^{14,15}$

\section{Medical Therapy Prior to Surgery}

Preoperative treatment to improve a patient's clinical status prior to surgery is rarely necessary unless there is a severe metabolic change caused by prolonged hypercortisolism. Ketoconazole is the drug of choice. It exerts its effect by blocking corticosteroid synthesis in the liver at the level of cytochrome P-450 enzyme. The administration of 600 to $800 \mathrm{mg} /$ day may decrease cortisol plasma levels with improvement in symptoms; however, side effects are not uncommon, thus precluding prolonged use of the drug. ${ }^{29,39}$ Four of the patients in the present study were taking ketoconazole prior to surgery.

\section{Surgical Technique}

All patients underwent a purely endoscopic endonasal surgery with a $0^{\circ}$ endoscope with a lens diameter of $4 \mathrm{~mm}$ (Karl Storz GmbH \& Co. KG). This approach has been described elsewhere ${ }^{9}$ but will be briefly discussed here. The operation takes place while a patient is supine with his or her head fixed in a three-pin Mayfield holder. The head of the bed is elevated, and the neck is slightly extended and rotated toward the right side. Frameless stereotactic navigation with the Stealth machine (Medtronic) is used for anatomical guidance. Note that $\mathrm{C}$-arm fluoroscopy is not used because neuronavigation has been proven highly reli- 
Purely endoscopic endonasal approach for Cushing disease

TABLE 1

Summary of characteristics in 25 patients with ACTH-secreting adenomas*

\begin{tabular}{|c|c|c|c|c|c|c|}
\hline Adenoma Type & $\begin{array}{l}\text { No. of } \\
\text { Cases }\end{array}$ & $\begin{array}{l}\text { Medical Treatment } \\
\text { Before Surgery }\end{array}$ & $\begin{array}{l}\text { Cases } \\
\text { of GTR }\end{array}$ & $\begin{array}{l}\text { Endo- } \\
\text { crine Cure }\end{array}$ & $\begin{array}{c}\text { Histological } \\
\text { Confirmation } \\
\text { of ACTH Cells }\end{array}$ & $\begin{array}{l}\text { Crooke } \\
\text { Cell }\end{array}$ \\
\hline $\begin{array}{l}\text { microadenoma } \\
\text { macroadenoma w/o }\end{array}$ & 13 & 1 & 13 & 13 & $12 \dagger$ & 3 \\
\hline cavernous invasion & 5 & 2 & 5 & 4 & 5 & 2 \\
\hline cavernous involvement & 2 & 1 & 0 & 0 & 2 & 0 \\
\hline \multirow{3}{*}{$\begin{array}{l}\text { nondiagnostic MRI } \\
\text { and IPPS } \dagger\end{array}$} & 5 & 0 & 3 adenectomy & 2 & $1 \ddagger$ & 0 \\
\hline & & & $\begin{array}{l}1 \text { hemihypophy- } \\
\text { sectomy }\end{array}$ & 1 & 0 & 0 \\
\hline & & & $\begin{array}{l}1 \text { nondiagnostic } \\
\text { exploration }\end{array}$ & 0 & 0 & \\
\hline total & 25 & $4(16)$ & $22(88) \S$ & $20(80)$ & $20(80)$ & $5(20)$ \\
\hline
\end{tabular}

able. ${ }^{10} \mathrm{~A}$ video monitor is positioned behind the patient's head directly in front of the surgeon's line of vision. After connecting the endoscope to the irrigating system (Clear Vision, Karl Storz), the endonasal approach is started, generally from the right nostril, and consists of resection (or lateralization) of the middle turbinate, large sphenoidotomy, and exposure of the sellar floor from carotid to carotid and craniocaudally from the planum to the clivus. For pituitary exploration and tumor removal, we advocate a binostril, bimanual technique that requires the resection of a small part of the posterior nasal septum. This procedure significantly increases the maneuverability of instruments, augments the efficacy and safety of endoscopic surgery by improving access to the tumor, and helps to deal with any bleeding in the same manner as is done with microsurgery. Drilling the base of the sphenoid, an important step in exposing the clivus and inferior sellar floor, and exposing the sellar floor are done using the bimanual technique, with the assistant surgeon holding the endoscope. On completion of the wide sphenoidotomy, the following anatomical structures in the sphenoid should be seen: clival and sellar carotid prominence, medial and lateral opticocarotid recess, planum, and clivus. A micro-Doppler probe is used to identify and confirm the trajectory of both carotid arteries. The dural opening is made from the medial cavernous sinus wall and from the superior intercavernous sinus to the clivus. With the binostril bimanual technique, tumor is removed using the same principles as with the microscopic technique. In cases of focal compression toward the cavernous sinus, tumor resection can be continued by carefully dissecting the lesion from the medial wall of the cavernous sinus, which can be easily seen via the endoscopic technique. Several tumors believed to be invasive based on MR imaging were found on surgical exploration to be compressing the medial wall of the cavernous sinus and were easily removed. True intracavernous invasion with tumor reaching and circumventing the carotid arteries precludes total resection, and thus a subtotal resection policy is adopted for these tumors.

If no tumor is identified on MR imaging, surgical exploration is performed based on the results of the IPSS. In all of these cases, both sides of the gland are explored. In the event of negative findings on exploration and in the context of a high interpetrosal ACTH concentration gradient, a hemihypophysectomy of the suspect side might be performed. We do not advocate a complete hypophysectomy.

Closure is performed in a multilayer fashion using Surgicel, fibrin glue, and Gelfoam. In cases of significant perioperative CSF leakage, fascia lata and fat grafts are harvested. No nasal packing is used with this technique. All patients are admitted to a step-down unit for overnight monitoring.

\section{Postoperative Workup and Definition of a Cure}

Steroids are not administered during surgery. An early basal cortisol level is determined the day after surgery, and other routine hormonal tests are conducted. In patients with a cortisol level lower than $100 \mathrm{nmol} / \mathrm{L}$, steroid coverage is commenced. In these patients, substitution therapy with hydrocortisone (30 mg daily) is prescribed. Patients are reevaluated at 6 to 8 weeks postoperatively and thereafter at 2 - to 3-month intervals during the 1st year after surgery. The patient is then followed up annually at our interdisciplinary pituitary clinic. At each visit, the fasting plasma cortisol concentration is measured after withdrawal of glucocorticoid substitution for 24 hours. In addition, a low-dose dexamethasone suppression test (1 mg overnight) is performed at 1 and 3 months after surgery, as is the measurement of the 24-hour UFC. These tests are repeated at each follow-up and earlier if recurrence of the hypercortisolism is suspected. In every patient in whom glucocorticoid substitution is started after surgery, an attempt is made to reduce the dose of oral glucocorticoids at 3 months after surgery and to stop glucocorticoid substitution within 12 to 24 months after surgery. After stopping steroid replacement, the integrity of the hypothalamic-pituitary-adrenal axis is assessed using the insulin-hypoglycemia test.

Patients are considered to be in endocrinological remission if all of the following criteria are met:1) an early basal cortisol level lower than $100 \mathrm{nmol} / \mathrm{L}$ after surgery; 2) suppression to low-dose dexamethasone test; and 3) normal- 


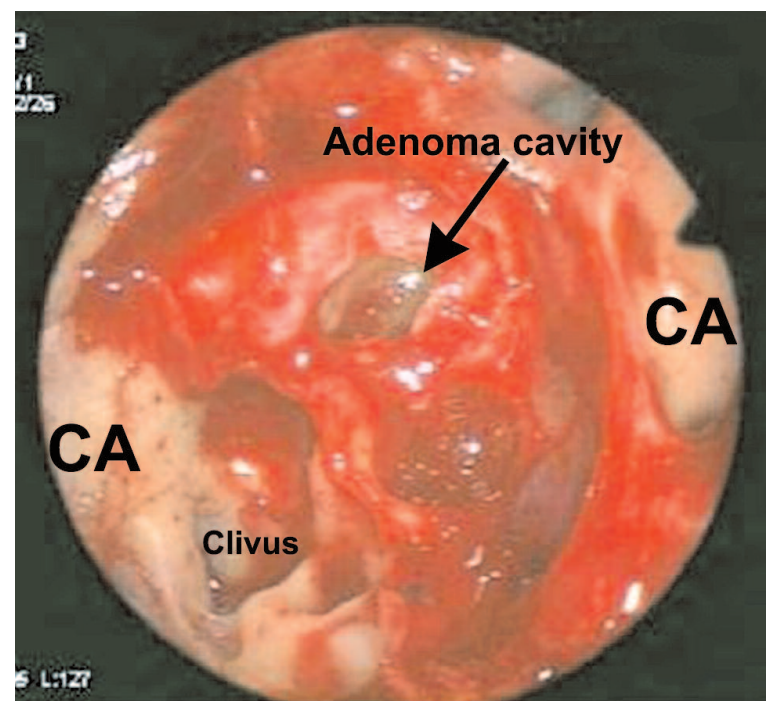

FIG. 2. Endoscopic view of the sellar region obtained after resection of an adenoma, demonstrating the carotid prominence bilaterally as well as the clivus and normal pituitary gland on the right side of the adenoma cavity. The patient was in remission after surgery.

ization of the 24-hour UFC on follow-up. The thyrotropic, gonadotropic, and somatotropic axis is assessed at regular intervals by measuring the serum concentrations of TSH, free thyroxine, LH, FSH, testosterone, estradiol, and IGF-1.

\section{Results}

Of the 25 patients, 19 were female and 6 male. The mean age at the time of the diagnosis was $42 \pm 12.5$ years. The MR imaging results clearly revealed a microadenoma in 13 patients and a macroadenoma in seven. In two patients with macroadenoma, there was evidence of cavernous sinus involvement (Table 1).

In five patients, a pituitary source for the hypercortisolism was identified based on the preoperative endocrine evaluation, but the MR imaging findings were unclear or normal despite imaging with a 3-tesla unit and dynamic infusion studies. The IPSS in all cases confirmed a pituitary origin together with a significant gradient between central and peripheral ACTH levels. Furthermore, an interpetrosal gradient toward the right sinus was found in three patients and toward the left sinus in one; there was no significant gradient in one patient.

Three patients had undergone prior surgery at other institutions, with incomplete removal or normal findings on exploration. Of these patients one with a macroadenoma had significant residual disease, one had evidence of a microadenoma on postoperative MR imaging, and the third had ambiguous MR imaging results and underwent IPSS.

In patients with positive MR imaging findings, the pure endoscopic approach permitted GTR in all except two patients with cavernous sinus invasion (Fig. 2). With one exception, all patients with microadenomas and those with macroadenomas without cavernous sinus invasion experienced remission after surgery. This patient with a macroadenoma, despite confirmed GTR on postoperative MR im- ages, continued to have postoperative cortisol levels above $100 \mathrm{nmol} / \mathrm{L}$ without the need for steroid replacement.

Among the subgroup of patients with normal MR imaging and IPSS results, surgical exploration revealed pathological tissue in three patients, with postoperative remission in two. Nodular corticotroph hyperplasia was diagnosed in the third patient, who did not have a remission. One patient with prior surgery underwent a hemihypophysectomy following a nondiagnostic exploration of the pituitary fossa. This patient had a remission after surgery. In the last patient in this subgroup, hemihypophysectomy was not pursued because of the discordance between the suspected side of abnormality on MR imaging and the side indicated by IPSS as well as a nondiagnostic exploration. This patient was not cured. The two patients with cavernous involvement had a significant decrease in cortisol levels after surgery but did not reach our criteria for remission. Postoperative assessment of endocrine function in the entire series revealed remission in 20 patients $(80 \%)$, including the three patients with residual or recurrent disease preoperatively. The median follow-up period was 17 months (range 2-33 months) after surgery. There was no instance of recurrence at the time of the last follow-up.

The main reasons for treatment failure in this study were extensive involvement of the cavernous sinus, nondiagnostic exploration, infiltrative disease, and the diagnosis of a nodular corticotroph hyperplasia.

\section{Histopathological Analysis}

Histological workup confirmed a pituitary adenoma in 21 of 25 patients. Among these 21 cases, the expression of the ACTH was proven with immunohistochemistry in all except one specimen, which was too small for precise examination. In five cases, Crooke cells were evident. ${ }^{31}$

Nodular corticotroph hyperplasia of the pituitary gland was found in one patient. In the remaining three patients, no tumor was identified. Among these patients was one in whom obvious abnormal tissue had been identified during surgery and in whom remission criteria were met despite normal histological features, one patient who underwent hemihypophysectomy, and one with a nondiagnostic exploration.

\section{Additional Treatment in Patients With Persistent Hypercortisolism}

Three patients with persistent disease were referred for conformal fractionated radiation and the one with nodular hyperplasia of the gland for bilateral adrenalectomy. One patient with persistent biochemical abnormality, but a significant decrease in cortisol levels and clinical improvement is being closely observed. The short-term follow-up period after radiation in the three patients precludes any realistic conclusion with regard to their outcomes.

\section{Length of Stay}

The average length of stay was $2.9 \pm 0.8$ days, with 16 patients $(64 \%)$ discharged 48 hours after the surgery. The major reasons for longer hospitalizations were transitory diabetes insipidus, suspicion of CSF leakage, and medical comorbidities. 


\section{Purely endoscopic endonasal approach for Cushing disease}

\section{Postoperative Complications}

There was no postoperative epistaxis or infection. Four patients had temporary crusting and mild discomfort after surgery. No patients presented with visual problems before or after surgery. One patient had a postoperative CSF leak, which responded to 3 days of lumbar drainage. In addition to the need for steroid replacement for hypocortisolism postoperatively, three patients required substitution thyroid replacement. Two of these patients also required estrogen and testosterone replacement. No other anterior pituitary insufficiency was identified. At the last follow-up, 12 of the 20 patients in remission still required full corticosteroid replacement therapy. One patient presented with transitory diabetes insipidus, which resolved before discharge. There was no surgery-related death or serious morbidity (meningitis and carotid artery injury).

\section{Discussion}

Surgery continues as the mainstay of treatment for Cushing disease. Data from numerous studies have confirmed that in experienced hands, surgery can result in high rates of remission with low complications compared with other treatment modalities. ${ }^{1-4,6,12,16,20,38}$ Surgery can lead to an immediate normalization of cortisol levels together with improvement in symptoms. It also has a role in reducing tumor size, improving the dosimetry of radiation therapy when necessary. Standard microsurgical transsphenoidal surgery is an excellent, well-established technique for the removal of most pituitary adenomas.

The endoscope is the most recent of many innovations that have contributed to the field of transsphenoidal surgery over the last three decades. The endoscopic approach allows the surgeon a wide panoramic view independent of the width and depth of the access. Jankowski and colleagues ${ }^{24}$ were the first to use a pure endonasal endoscopic approach for the removal of pituitary adenomas. More recently, the technique has been further refined and popularized by several other authors. ${ }^{8,9,17,19,25}$ Early reports on this technique have highlighted the endoscope's superior visualization over the operative microscope and have suggested that this more minimally invasive technique allows more complete tumor removal and a reduced rate of complications. Some concerns have been raised about the endoscope: namely, the lack of stereoscopic view and the reduced maneuverability. Although there may be some validity to these concerns when using the one-nostril, onehand technique, use of the binostril, bimanual technique described in this report along with training and the learning curve can markedly minimize these disadvantages.

Due to its relatively recent introduction, there are only a few reports on a large series of patients with functioning pituitary tumors treated via a purely endoscopic approach. ${ }^{8,19,25,26,32}$ Data in these studies suggest at least equivalent or even superior results to those offered by microscopic techniques. ${ }^{19,26}$

\section{Remission Rates}

In the present study, we report the early results of endoscopic pituitary surgery in 25 consecutive patients treated at our center. Remission of hypercortisolism was achieved in $80 \%$ of the patients. None of the patients has presented with recurrence at a median follow-up of 17 months. Remission rates after transsphenoidal surgery for Cushing disease vary significantly among studies, ranging from 42 to $95 \%$, with most between 70 and $85 \%$. There has been no significant improvement in remission rates over the past years, although they are strongly dependent on the remission criteria used. There is a higher remission rate when an adenoma is found intraoperatively than when there is a nondiagnostic exploration with or without hemihypophysectomy. ${ }^{18}$ In a comparison of micro- and macroadenomas, there are improved remission rates in the former group. ${ }^{11,41}$ The number of cases in our series is too small in each of the abovementioned subcategories to confirm these findings. The remission rate following surgery for recurrent tumors is less than that for primary tumors. Nevertheless, the three patients in the present study who had previous surgery were cured after the second surgery.

With regard to endoscopic series, Cappabianca et al. ${ }^{8}$ reported on 87 patients with various pituitary adenomas, including eight patients with Cushing disease, treated with endoscopic transsphenoidal surgery. The remission criteria for patients with Cushing disease included restoration of the circadian rhythm of cortisol and the normalization of urinary cortisol levels. Only one patient (with a microadenoma) in this series remained hypercortisolemic after the pituitary operation and received additional treatment with bilateral adrenalectomy. In the series of 128 patients described by Jho, ${ }^{25}$ there were 16 patients with Cushing disease, and $70 \%$ of them had normal (subnormal) cortisol levels after the surgical treatment. Note, however, that the postoperative endocrinological assessment was not reported in depth.

Recently, Netea-Maier et al. ${ }^{32}$ reported on their series of 35 patients with Cushing disease treated endoscopically. They had a remission rate of $77 \%$ after the first surgery and $83 \%$ when surgery was repeated for initial failures. Their follow-up period ranged from 4 to 81 months (median 20 months). Our remission rate is comparable to that in the previous series, showing good early functional outcomes after a purely endoscopic resection of ACTH-secreting tumors. One must consider that one of the treatment failures in our study was due to the development of a diffuse nodular hyperplasia of the pituitary gland rather than a failure to treat the adenoma itself. Excluding this case from our series, the early remission rate would be $83 \%$.

Two of the patients in our study who were considered in remission had no histological confirmation of the tumor. In one of them an adenoma was found during surgery, and the other one underwent a hemihypophysectomy. Although there is no clear explanation for their cure, Sheehan et al. ${ }^{36}$ have shown that the results of surgery in terms of a cure rate for Cushing disease in patients with normal histological features do not differ significantly from those with confirmed adenoma. ${ }^{8,25,32}$

\section{Recurrence Rates}

Reported recurrence rates in Cushing disease have ranged from 3.4 to $63 \%$ and are significantly higher for macroadenomas. ${ }^{1,4,6,13,21,23,36,38,40,41,47}$ The time between opera- 
tion and recurrence has ranged between 16 months and 10 years during a mean follow-up period of 3 months to 7 years. The incidence of recurrent disease increases with the duration of the observation period. Although our short-term follow-up precludes any strong conclusions with regard to long-term outcomes in our series, the strict criteria used for the definition of a cure in this study have generally correlated with a high chance of long-term remission and a low likelihood of recurrence. . $^{13,34,43}$

\section{Complication Rates}

Morbidity rates following surgery for Cushing disease have been reported to be between 0 and 53\%. . $^{1,4,12,23,30,35,38,42}$ Major complications have included CSF leakage, meningitis, sinusitis, pulmonary embolism, deep vein thrombosis, anterior or posterior pituitary insufficiency, visual deficit, cranial nerve palsies, and nasal septum perforation. Cappabianca and colleagues ${ }^{7}$ have reported lower complication rates in a general population with pituitary adenomas following endoscopic endonasal surgery as compared with after microscopic techniques. Netea-Maier and associates ${ }^{32}$ reported three cases with CSF leak and one with severe epistaxis among their series of 35 patients endoscopically treated for Cushing disease. Our low complication rate in the present series, in keeping with previous endoscopic reports, confirms the safety of this technique.

Although mortality rates of up to $8.4 \%$ have been reported following surgery, ${ }^{30}$ there have been no deaths in the more recent series or in the present study.

\section{Pituitary Function}

Hypocortisolism after surgery is a good prognostic factor predicting remission and a lower risk of recurrence. The disorder may persist due to adrenal insufficiency caused by long-term suppression of normal pituitary tissue. Persistent hypocortisolism reportedly ranges from 1.7 to $44 \%$., 138,42 Other persistent endocrine deficits have been reported in up to $70 \%$ of cases. ${ }^{11,12,23}$ Even in some newer studies, the incidence exceeds $25 \%$. The main reason for this relatively high rate of pituitary dysfunction may be attributable to injury to the normal pituitary gland during aggressive tumor removal or exploration of the gland in an attempt to achieve a cure. In their endoscopic study, Netea-Maier et al. ${ }^{32}$ reported postoperative anterior pituitary deficits of $34 \%$ and posterior pituitary insufficiency of $6 \%$, requiring substitution therapy. We encountered three new cases of anterior pituitary deficiency (12\%) and one of transient diabetes insipidus that resolved after temporary treatment with vasopressin. We attribute this very low rate of pituitary insufficiency to improved visualization of the pituitary fossa and gland, which decreases the necessity for over-manipulation of the gland.

\section{Tolerance and the Hospital Stay}

Postoperative pain was minimal with no need for nasal packing, thus making the patient much more comfortable after surgery. ${ }^{19,37}$ Authors of a recent report reconfirmed patients' better comfort after endoscopic surgery. ${ }^{17}$ The length of stay has been shown to be shorter ${ }^{22}$ than that after a microscopic procedure, and this finding was confirmed by our observation (2.9 days compared with 5.8 days; the lat- ter figure represents the median hospital stay in a previous study of the standard microscopic technique; unpublished data). The duration of hospitalization might be as short as for endoscopic surgery in the hands of experienced neurosurgeons; therefore, based on the results of the present study we can conclude that the hospital stay is similar to that for the standard microscopic approach. Endoscopic pituitary surgery has minimal impact on a patient's quality of life (Karabatsou et al., unpublished data).

\section{Limitations of This Study}

The number of patients in this study is limited because of the relatively recent application of a purely endoscopic technique at our center. Although the early results of endoscopic pituitary surgery for Cushing disease are promising, a random allocation of patients into endoscopic and microscopic treatment groups would have been the best method of showing the superiority of one or the other of these approaches. Our very satisfying experience with the endoscopic technique encouraged us to expand our experience and not to randomize patients into the two different approaches.

The follow-up in this study is short, with a median period of 17 months. Recurrence of ACTH-secreting adenomas in patients previously assumed to be cured has been reported. 1,4,6,13,21,23,36,38,40,41,47 The use of very strict criteria in defining remission or cure, as in our series, can reduce the likelihood of recurrence. ${ }^{13,34,43}$ At present, there are no data to prove that the endoscopic technique results in a lower incidence of delayed recurrence.

\section{Conclusions}

Endoscopic transsphenoidal pituitary surgery in patients with Cushing disease can lead to a high early postoperative remission rate similar to those reported by experienced surgeons using conventional microscopic or endoscopic techniques. Surgical complications and patient discomfort were minimal. Although long-term control data and a prospective analysis of a surgical series are required to strengthen our conclusions, the advantages of the endoscopic technique - the improved view and illumination, lower complication rates, and shorter hospital stay-along with the favorable results of other similar series make this technique very attractive and perhaps the favored approach for the treatment of Cushing disease.

\section{References}

1. Bakiri F, Tatai S, Aouali R, Semrouni M, Derome P, Chitour F, et al: Treatment of Cushing's disease by transsphenoidal, pituitary microsurgery: prognosis factors and long-term follow-up. J Endocrinol Invest 19:572-580, 1996

2. Barbetta L, Dall'Asta C, Tomei G, Locatelli M, Giovanelli M, Ambrosi B: Assessment of cure and recurrence after pituitary surgery for Cushing's disease. Acta Neurochir (Wien) 143: 477-482, 2001

3. Blevins LS Jr, Christy JH, Khajavi M, Tindall GT: Outcomes of therapy for Cushing's disease due to adrenocorticotropin-secreting pituitary macroadenomas. J Clin Endocrinol Metab 83: 63-67, 1998

4. Bochicchio D, Losa M, Buchfelder M: Factors influencing the immediate and late outcome of Cushing's disease treated by transsphenoidal surgery: a retrospective study by the European 
Cushing's Disease Survey Group. J Clin Endocrinol Metab 80: 3114-3120, 1995

5. Brown RL, Weiss RE: An approach to the evaluation and treatment of Cushing's disease. Expert Rev Anticancer Ther 6 (9 Suppl):S37-S46, 2006

6. Cannavò S, Almoto B, Dall'Asta C, Corsello S, Lovicu RM, De Menis E, et al: Long-term results of treatment in patients with ACTH-secreting pituitary macroadenomas. Eur J Endocrinol 149:195-200, 2003

7. Cappabianca P, Cavallo LM, Colao A, de Divitiis E: Surgical complications associated with the endoscopic endonasal transsphenoidal approach for pituitary adenomas. J Neurosurg 97:293-298, 2002

8. Cappabianca P, Cavallo LM, Colao A, Del Basso De Caro M, Esposito F, et al: Endoscopic endonasal transsphenoidal approach: outcome analysis of 100 consecutive procedures. Minim Invasive Neurosurg 45: 193-200, 2002

9. Cappabianca P, Cavallo LM, Esposito F, de Divitiis E: Endoscopic endonasal transsphenoidal surgery: procedure, endoscopic equipment and instrumentation. Childs Nerv Syst 20:796-801, 2004

10. Carvi MN, Hollerhage HG: Reliability of neuronavigation-assisted trans-sphenoidal tumor resections. Neurol Res [epub ahead of print], 2007

11. Chandler WF, Schteingart DE, Lloyd RV, McKeever PE, IbarraPerez G: Surgical treatment of Cushing's disease. J Neurosurg 66:204-212, 1987

12. Chee GH, Mathias DB, James RA, Kendall-Taylor P: Transsphenoidal pituitary surgery in Cushing's disease: can we predict outcome? Clin Endocrinol (Oxf) 54:617-626, 2001

13. Chen JC, Amar AP, Choi S, Singer P, Couldwell WT, Weiss MH: Transsphenoidal microsurgical treatment of Cushing disease: postoperative assessment of surgical efficacy by application of an overnight low-dose dexamethasone suppression test. J Neurosurg 98:967-973, 2003

14. Colao A, Faggiano A, Pivonello R, Pecori Giraldi F, Cavagnini F, Lombardi G, et al: Inferior petrosal sinus sampling in the differential diagnosis of Cushing's syndrome: results of an Italian multicenter study. Eur J Endocrinol 144:499-507, 2001

15. de Herder WW, Uitterlinden P, Pieterman H, Tanghe HL, Kwekkeboom DJ, Pols HA, et al: Pituitary tumor localization in patients with Cushing's disease by magnetic resonance imaging. Is there a place for petrosal sinus sampling? Clin Endocrinol (Oxf) 40:87-92, 1994

16. Dickerman RD, Oldfield EH: Basis of persistent and recurrent Cushing disease: an analysis of findings at repeated pituitary surgery. J Neurosurg 97:1343-1349, 2002

17. Dusick JR, Esposito F, Mattozo CA, Chaloner C, McArthur DL, Kelly DF: Endonasal transsphenoidal surgery: the patient's perspective-survey results from 259 patients. Surg Neurol 65:332-342, 2006

18. Dyer EH, Civit $\mathrm{T}$, Visot A, Delalande O, Derome P: Transsphenoidal surgery for pituitary adenomas in children. Neurosurgery 34:207-212, 1994

19. Frank G, Pasquini E, Farneti G, Mazzatenta D, Sciarretta V, Grasso V, et al: The endoscopic versus the traditional approach in pituitary surgery. Neuroendocrinology 83:240-248, 2006

20. Friedman RB, Oldfield EH, Nieman LK, Chrousos GP, Doppman JL, Cutler GB Jr, et al: Repeat transsphenoidal surgery for Cushing's disease. J Neurosurg 71:520-527, 1989

21. Hammer GD, Tyrrell JB, Lamborn KR, Applebury CB, Hannegan ET, Bell S, et al: Transsphenoidal microsurgery for Cushing's disease: initial outcome and long-term results. J Clin Endocrinol Metab 89:6348-6357, 2004

22. Har-El G: Endoscopic transnasal transsphenoidal pituitary surgery-comparison with the traditional sublabial transseptal approach. Otolaryngol Clin North Am 38:723-735, 2005

23. Höybye C, Grenbäck E, Thorén M, Hulting AL, Lundblad L, von Holst $\mathrm{H}$, et al: Transsphenoidal surgery in Cushing disease: 10 years of experience in 34 consecutive cases. J Neurosurg 100:634-638, 2004

24. Jankowski R, Auque J, Simon C, Marchal JC, Hepner H, Wayoff M: Endoscopic pituitary tumor surgery. Laryngoscope 102:198-202, 1992

25. Jho HD: Endoscopic transsphenoidal surgery. J Neurooncol 54:187-195, 2001

26. Kabil MS, Eby JB, Shahinian HK: Fully endoscopic endonasal vs. transseptal transsphenoidal pituitary surgery. Minim Invasive Neurosurg 48:348-354, 2005

27. Liddle GW: Tests of pituitary-adrenal suppressibility in the diagnosis of Cushing's syndrome. J Clin Endocrinol Metab 20:1539-1560, 1960

28. Lindholm J, Juul S, Jorgensen JO, Astrup J, Bjerre P, FeldtRasmussen U, et al: Incidence and late prognosis of cushing's syndrome: a population-based study. J Clin Endocrinol Metab 86:117-123, 2001

29. Loli P, Berselli ME, Tagliaferri M: Use of ketoconazole in the treatment of Cushing's syndrome. J Clin Endocrinol Metab 63:1365-1371, 1986

30. Mampalam TJ, Tyrrell JB, Wilson CB: Transsphenoidal microsurgery for Cushing disease. A report of 216 cases. Ann Intern Med 109:487-493, 1988

31. Martin R, Cetin Y, Fehm HL, Fahlbusch R, Voigt KH: Multiple cellular forms of corticotrophs in surgically removed pituitary adenomas and periadenomatous tissue in Cushing's disease. Am J Pathol 106:332-341, 1982

32. Netea-Maier RT, van Lindert EJ, den Heijer M, van der Eerden A, Pieters GF, Sweep CG, et al: Transsphenoidal pituitary surgery via the endoscopic technique: results in 35 consecutive patients with Cushing's disease. Eur J Endocrinol 154:675-684, 2006

33. Oldfield EH, Chrousos GP, Schulte HM, Schaaf M, McKeever PE, Krudy AG, et al: Preoperative lateralization of ACTH-secreting pituitary microadenomas by bilateral and simultaneous inferior petrosal venous sinus sampling. N Engl J Med 312:100-103, 1985

34. Pereira AM, van Aken MO, van Dulken H, Schutte PJ, Biermasz NR, Smit JW, et al: Long-term predictive value of postsurgical cortisol concentrations for cure and risk of recurrence in Cushing's disease. J Clin Endocrinol Metab 88:5858-5864, 2003

35. Semple PL, Laws ER Jr: Complications in a contemporary series of patients who underwent transsphenoidal surgery for Cushing's disease. J Neurosurg 91:175-179, 1999

36. Sheehan JM, Lopes MB, Sheehan JP, Ellegala D, Webb KM, Laws ER Jr: Results of transsphenoidal surgery for Cushing's disease in patients with no histologically confirmed tumor. Neurosurgery 47:33-39, 2000

37. Sheehan MT, Atkinson JL, Kasperbauer JL, Erickson BJ, Nippoldt TB: Preliminary comparison of the endoscopic transnasal vs the sublabial transseptal approach for clinically nonfunctioning pituitary macroadenomas. Mayo Clin Proc 74:661-670, 1999

38. Shimon I, Ram Z, Cohen ZR, Hadani M: Transsphenoidal surgery for Cushing's disease: endocrinological follow-up monitoring of 82 patients. Neurosurgery 51:57-62, 2002

39. Sonino N, Boscaro M, Paoletta A, Mantero F, Ziliotto D: Ketoconazole treatment in Cushing's syndrome: experience in 34 patients. Clin Endocrinol (Oxf) 35:347-352, 1991

40. Sonino N, Zielezny M, Fava GA, Fallo F, Boscaro M: Risk factors and long-term outcome in pituitary-dependent Cushing's disease. J Clin Endocrinol Metab 81:2647-2652, 1996

41. Stevénaert A, Perrin G, Martin D, Beckers A: [Cushing's disease and corticotrophic adenoma: results of pituitary microsurgery.] Neurochirurgie 48:234-265, 2002 (Fr)

42. Tindall GT, Herring CJ, Clark RV, Adams DA, Watts NB: Cushing's disease: results of transsphenoidal microsurgery with emphasis on surgical failures. J Neurosurg 72:363-369, 1990

43. Toms GC, McCarthy MI, Niven MJ, Orteu CH, King TT, Monson 
JP: Predicting relapse after transsphenoidal surgery for Cushing's disease. J Clin Endocrinol Metab 76:291-294, 1993

44. Tyrrell JB, Findling JW, Aron DC, Fitzgerald PA, Forsham PH: An overnight high-dose dexamethasone suppression test for rapid differential diagnosis of Cushing's syndrome. Ann Intern Med 104:180-186, 1986

45. Utz AL, Swearingen B, Biller BM: Pituitary surgery and postoperative management in Cushing's disease. Endocrinol Metab Clin North Am 34:459-478, 2005

46. Vidal Trecan G, Laudat MH, Thomopoulos P, Luton JP, Bricaire $\mathrm{H}$ : Urinary free corticoids: an evaluation of their usefulness in the diagnosis of Cushing's syndrome. Acta Endocrinol (Copenh) 103:110-115, 1983
47. Yap LB, Turner HE, Adams CB, Wass JA: Undetectable postoperative cortisol does not always predict long-term remission in Cushing's disease: a single centre audit. Clin Endocrinol (Oxf) 56:25-31, 2002

Manuscript submitted June 19, 2007.

Accepted August 7, 2007.

Address correspondence to: Amir R. Dehdashti, M.D., Division of Neurosurgery, Toronto Western Hospital, Fourth Floor, West Wing, 399 Bathurst Street, M5T 2S8, Toronto, Ontario, Canada. email: amirdehdashti@hotmail.com. 